\title{
An application of a Markov-chain model of shore erosion for describing the dynamics of sediment flux
}

Received: 12 October 2003 / Accepted: 2 August 2004/Published online: 28 January 2005

(C) Springer-Verlag 2005

\begin{abstract}
Acquisition of coastline retreat rate time sequences (RRTS) is an important component of Arctic coastal monitoring. These data can be used not only to estimate sediment input into the sea during a fixed time period, but also to dynamically simulate sediment flux intensity. The RRTS were investigated at the Marre-Sale (Kara Sea) and Malii Chukochii Cape (East Siberian Sea) key sites. Statistical analysis demonstrated that the RRTS possess Markov characteristic. This allowed coastline dynamics to be described using a Markovchain model. A model is discussed that combines Markov characteristic and information about the composition and structure of the permafrost sediments to describe sediment flux dynamics.
\end{abstract}

\section{Introduction}

Coastline retreat rates exhibit high temporal variability in permafrost regions. Typical values for coastline retreat rate (hereafter CLRR) are on the order of a few meters per year (Are 1988, 1998). This rate of erosion gives a corresponding sediment flux intensity (SFI) into the sea that ranges up to several tens of tons per meter and year, depending on the cliff height as well as the ice content and density of the eroding deposits. The data of Razumov (1996), Pavlidis and

\footnotetext{
V. Ostroumov $(\varangle) \cdot$ V. Sorokovikov

Institute of Physicochamical and Biological

Problems of Soil Science RAS, 2, Institutskaya St.,

Pushchino, Moscow, 142292, Russia

E-mail: v.ostroumov@rambler.ru

Tel.: + 7-096-7732604

Fax: + 7-096-7330595

V. Rachold

Research Unit Potsdam, Alfred Wegener Institute, Telegrafenberg A43, 14473 Potsdam, Germany

A. Vasiliev

Earth Cryosphere Institute SB RAS,

90/6, Vavilova St., Moscow, 117982, Russia
}

Leont'ev (2002), Shur et al. (1984), Rachold et al. (2003) and others allow calculation of the average SFI values, which are evaluated as $35-42 \mathrm{t} \mathrm{m}^{-1}$ per year for the East-Siberian Sea shore and $48-56 \mathrm{t} \mathrm{m}^{-1}$ per year for the Kara Sea Shore. The greatest observed CLRR is about $110 \mathrm{~m}$ per year (Zigarev and Sovershaev 1984). The associated values for SFI reach $750 \mathrm{t} \mathrm{m}^{-1}$ per year, given sediments with approximately $80 \%$ volumetric ice content. Such an ice content is typical for the Novosibirskiye Islands, where maximum CLRR values are observed. A dampening of shore erosion activity is accompanied by stabilization of the coastline; in this situation the SFI becomes zero (Are 1979). Other researchers also indicate that spatial and temporal variability is typical for both SFI and CLRR (e.g. Shur et al. 1984; Are 1988; Solomon 2003). Thus, values of SFI can range from zero up to many hundreds of tons per meter and year.

Models describing factors that influence shore erosion intensity can be divided into two groups. The first group is concerned with purely hydrodynamic considerations, and the models focus on changes in matter and energy flows, such as the underwater transport of suspended particles (Klimovich and Prokoviev 2002), the impact of ocean wave energy (e.g. Zenkovich 1946), heat transfer in the 'permafrost sediment-marine water' system (e.g. Balobaev 1984; Malinovskii 1982; Shur et al. 1984), and other elementary dynamical processes. The complexity of interaction amongst these processes makes it very difficult to develop a "common" model of shore erosion within the framework of the given approach (Are 1985). Models of the second group are based on empirical relationships (e.g. Are 1985; Razumov 1996, 2001). These models allow the shore erosion process to be described as a whole; however, they reflect stationary conditions. They cannot completely reflect dynamic aspects, and their practical use is complicated by the necessity of determining numerous empirical coefficients.

Like many other complex processes, the dynamics of CLRR is partly random in character. However, little attention has been given to the stochastic aspect. 
Developments in stochastic and comprehensive modeling approaches have allowed an expansion of simulation capabilities in this field. In this paper, the dynamics of SFI is described using a Markov-chain based model of coastal retreat. This approach is possible because it can be shown that the RRTS possesses Markov characteristics.

\section{Objectives, methods and results of monitoring}

\section{Objectives}

The objective of our activity is a simulation of the SFI dynamics, allowing for a stochastic element in temporal changes of shore destruction rate. Monitoring at the ACD profiles shows that seasons of low-intensity coastal erosion usually follow high-intensity seasons. In seasons with high CLRR, the eroded material is accumulated at the foot of the cliffs. It protects the cliffs from the wave's destroying effect during the following season and decreases the erosion intensity. Thus it is possible that the probability of high erosion intensity for each current season is determined by the erosion intensity during previous seasons. A relationship between the probability of a current condition and the previous condition can be used for dynamic modeling of the CLRR. Thus, making a test of the year-by-year dynamics of the CLRR time sequences for Markov characteristic is an important task. The next task is the development of standard calculation procedures for simulation of the time series used in monitoring data as the basis of the Markov model. Also simulated and observable time series have to be compared to evaluate the adequacy of the Markov model of the SFI dynamics.

\section{Coastal monitoring at the key sites}

The observation time series of the CLRR are examined for two sites of the ACD monitoring net. The first site, Marre-Sale, is located on the western shore of the Yamal Peninsula, Kara Sea. The second one, the Malii Chokochii Cape, is a typical coastal section of the Kolyma Lowland, East Siberian Sea. Both sites are in the continuous permafrost zone (Table 1). A shallow sea floor is an important factor in coastal erosion, as are a short ice-free period and the dominance of northern wind in the summer.

The Marre-Sale site is situated along a 4-km section of shoreline on the Kara Sea, south of the mouth of the Marrejaha River. The permafrost sediments are a mix of terrestrial/marine and marine muds and clays. The elevation range is $4-29 \mathrm{~m}$ above sea level. The permafrost sediments at this location possess a volumetric ice content of 0.4-0.5 (Shur et al. 1984; Sovershaev 1997; Vasiliev and Sautkin 1992). Thermal erosion accelerated with wave impact and slumping are the main mechanisms of coastal degradation at the Marre-Sale
Table 1 Some characteristics of the coastal monitoring sites

\begin{tabular}{|c|c|c|}
\hline & Marre-sale & $\begin{array}{l}\text { Malii Chukochii } \\
\text { Cape }\end{array}$ \\
\hline $\begin{array}{l}\text { Average air } \\
\text { temperature, } \mathrm{C}\end{array}$ & -8.6 & -13.8 \\
\hline $\begin{array}{l}\text { Temperature } \\
\text { of the permafrost, } \mathrm{C}\end{array}$ & -5.0 to -7.0 & -10.5 to -11.2 \\
\hline $\begin{array}{l}\text { Duration of the ice-free } \\
\text { period, days }\end{array}$ & 75 to 90 & 45 to 60 \\
\hline $\begin{array}{l}\text { Distance to the } 10-\mathrm{m} \\
\text { isobath, } \mathrm{km}\end{array}$ & 3 to 7 & 45 to 95 \\
\hline Minimal CLRR (m per year) & 0 & 0 \\
\hline Maximal CLRR (m per year) & 7.8 & 7.4 \\
\hline Typical CLRR (m per year) & 1.3 to 1.8 & 0.8 to 1.4 \\
\hline Start of monitoring, year & 1966 & 1974 \\
\hline
\end{tabular}

site (Vasiliev et al. 2003). Coastal monitoring at MarreSale is carried out along 55 profiles. An example of the data used for model testing, taken from seven profiles at the Marre-Sale key site, is presented in Fig. 1a. A detailed characterization of coastal erosion processes and environmental parameters at the site can be found in Shur et al. (1984), Vasiliev et al. (2001, 2002, 2003, 2004), Pavlov (1998), Pavlov et al. (1995), Shur (1984), Trofimov (1975) and Sovershaev (1997).

The Malii Chukochii Cape key site is located in the western Kolyma Lowland. It is situated along a $3-\mathrm{km}$ section of shoreline on the extreme western part of the Kolyma Gulf, East Siberian Sea, southeast of the mouth of the Chukochya River. The permafrost deposits are basically ice-rich muds containing ice wedges (Yedomic Suite, upper Pleistocene). They are exposed in a cliff that exceeds $30 \mathrm{~m}$ in height. These sediments are typical of the Arctic lowlands of northeastern Eurasia. Elevations exceed $41 \mathrm{~m}$ above sea level in places and the base of the ice complex is below sea level (Gilichinskii 2002). The permafrost layer was formed as a syncryogenic continental sediment of an alluvial and lake-bog origin. This material consists of mud with peat lenses. Alongside the ice complex sediments, secondary frozen deposits are typical for thermokarst depressions. These deposits have variable cryogenic age and can be characterized as relatively compressed permafrost sediments with lower ice content. There are small, epicryogenic ice wedges in the secondary frozen deposits of the thermokarst depressions. The most intense coastal destruction is observed under wave impact during wind-induced storms surges (Razumov 1996). The thermal degradation of the permafrost sediment plays a minor role at the subaerial part of the cliff. It can be explained by the short ice-free period and by the low seawater temperature in summer (Pavlidis and Loent'ev 2002). The properties of the site deposits used in the calculations are listed in Table 2.

The peculiarities of shore erosion at the Malii Chukochii Cape key site were investigated by Gubin, Gilichinskii (Kholodov et al. (2004) and by Razumov (1996). Permafrost characteristics of the Kolyma Lowland and the evolution of the land-sea system have been described by various researchers (Arkhangelov 1977; 


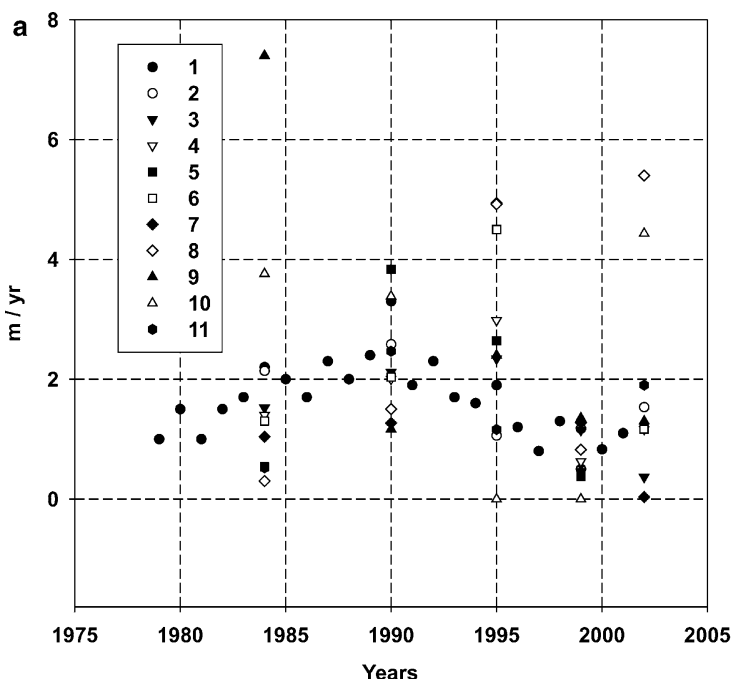

Fig. 1 An example of measured coastline retreat rates (m per year), data from coastal monitoring profiles (numbers) at the key sites Marre-Sale a and Malii Chokochii Cape b

Sher 1997; Gilichinskii 2002; Pavlidis and Leont'ev 2002; Danilov et al. 1997, 2000; Pfeiffer and Jansson 1994.

Estimation of the intensity of sediment flux

The sediment flux intensity $Q$ is expressed as tons of material removed from a unit section $(1, \mathrm{~m})$ of shoreline per year. The basic form of the relationship describes SFI in terms of the thickness of the eroded layer of permafrost sediment $(\mathrm{H}, \mathrm{m}), \mathrm{CLRR}(v, \mathrm{~m}$ per year), and volumetric density of the deposit $\left(\delta, \mathrm{t} \mathrm{m}^{-3}\right)$ as:

$Q=H \cdot v \cdot \delta$.

The influence of possible changes in slope morphology on the CLRR was not taken into account here. It is factored in during the development and testing of the model.

The thickness of the layer being eroded by shore erosion is considered to include both the height of the subaerial cliff and the depth of the underwater part of the cliff (Are 1985). The rate of destruction of the underwater part of the slope has a large delay with respect to the destruction of the subaerial cliff, due to the narrow width of the coastal band at the key sites. This makes it difficult to take into account the contribution of

Table 2 Properties of permafrost deposits used in calculations (Malii Chukochii Cape key site)

\begin{tabular}{lll}
\hline & $\begin{array}{l}\text { Sediments } \\
\text { of ice complex }\end{array}$ & $\begin{array}{l}\text { Deposits } \\
\text { of the thermokarst } \\
\text { depressions }\end{array}$ \\
\hline $\begin{array}{c}\text { Volumetric } \\
\text { density }\left(\mathrm{t} / \mathrm{m}^{3} \text { ) }\right.\end{array}$ & $1.3-1.5$ & $1.4-1.7$ \\
$\begin{array}{c}\text { Ice content within ice } \\
\text { wedge polygons (by volume) }\end{array}$ & $0.3-0.4$ & $0.2-0.3$ \\
$\begin{array}{c}\text { Ice content in ice wedges } \\
\text { (by volume) }\end{array}$ & $0.4-0.5$ & $0.1-0.15$ \\
\hline
\end{tabular}

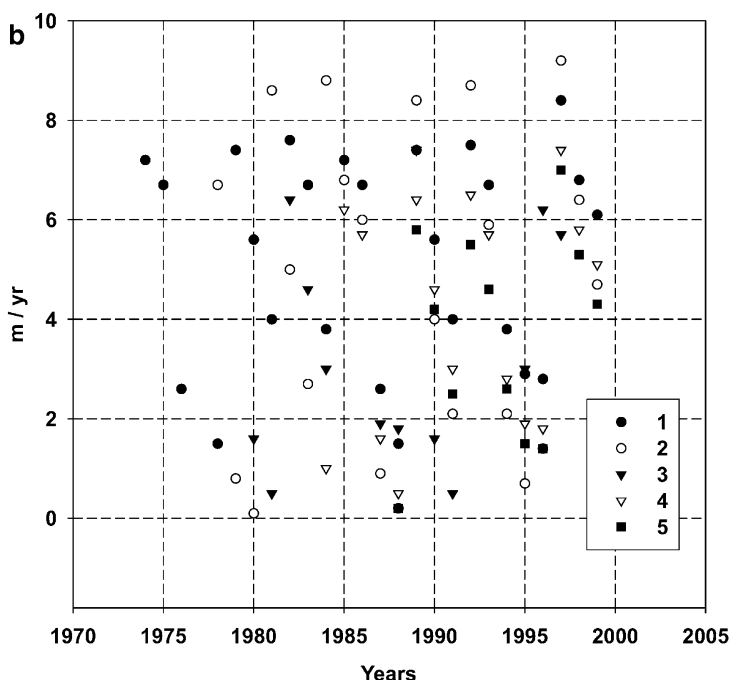

underwater erosion to the total flux. Furthermore, it is relatively small at the sites under consideration here. Due to these facts, the tradition has developed to evaluate sediment flux into a sea basin without the contribution from underwater erosion. Thus only the contribution of the subaerial cliff to the SFI is considered in this work. Given this, it must be remembered that the resulting estimates of SFI based on this approach will underestimate the actual flux intensity.

An estimate of the overall volumetric density $\delta$ $\left(\mathrm{t} \mathrm{m}^{-3}\right)$ of the permafrost sediment is determined using dry volumetric density $\gamma\left(\mathrm{t} \mathrm{m}^{-3}\right)$ and the total ice content. According to Brown and Solomon (2000), the contribution of ice wedges and texture ice should be considered separately. Overall volumetric density depends on the contents of the texture ice per unit of ground volume $L_{\mathrm{ti}}$ $\left(\mathrm{t} \mathrm{m}^{-3}\right)$ and ice wedges $L_{\mathrm{wi}}\left(\mathrm{t} \mathrm{m}^{-3}\right)$ as:

$\delta=\gamma \cdot\left(1-\frac{L_{\mathrm{ti}}}{\rho_{\mathrm{ti}}}-\frac{L_{\mathrm{wi}}}{\rho_{\mathrm{wi}}}\right)$,

where, $\rho_{\mathrm{ti}}=$ density of the texture ice, $\mathrm{t} \mathrm{m}^{-3}$ and $\rho_{\mathrm{wi}}=$ density of ice in wedges, $\mathrm{t} \mathrm{m}^{-3}$.

Data on the mean thickness of ice wedges $\left(l_{i}, \mathrm{~m}\right)$ and the distance between them $\left(l_{g}, \mathrm{~m}\right)$ in a polygonal network were used to calculate the contents of ice in wedges. It was assumed for simplicity that the icewedge polygons form squares in their plan section. Estimates of $\delta$ will be lower using this assumption than if the more typical rectangular shape were used. This will tend to underestimate values of $\delta$, which will correspondingly underestimate SFI. Measurements of $l_{g}$ and $l_{i}$ were conducted at key sites. The volumetric contents of wedge ice is

$\frac{L_{\mathrm{wi}}}{\rho_{\mathrm{wi}}}=\frac{l_{i}^{2}+2 \cdot l_{g} \cdot l_{i}}{l_{i}^{2}+2 \cdot l_{g} \cdot l_{i}+l_{g}^{2}}$.

The nomogram (Fig. 2) shows how the size and spacing of ice wedges influences the ice content. The mean ground ice content was determined using the weight technique to provide the content of pore ice. The content 
Fig. 2 Nomogram illustrating the relationship between size and spacing of ice wedges and total volumetric ground ice content. See text for explanation

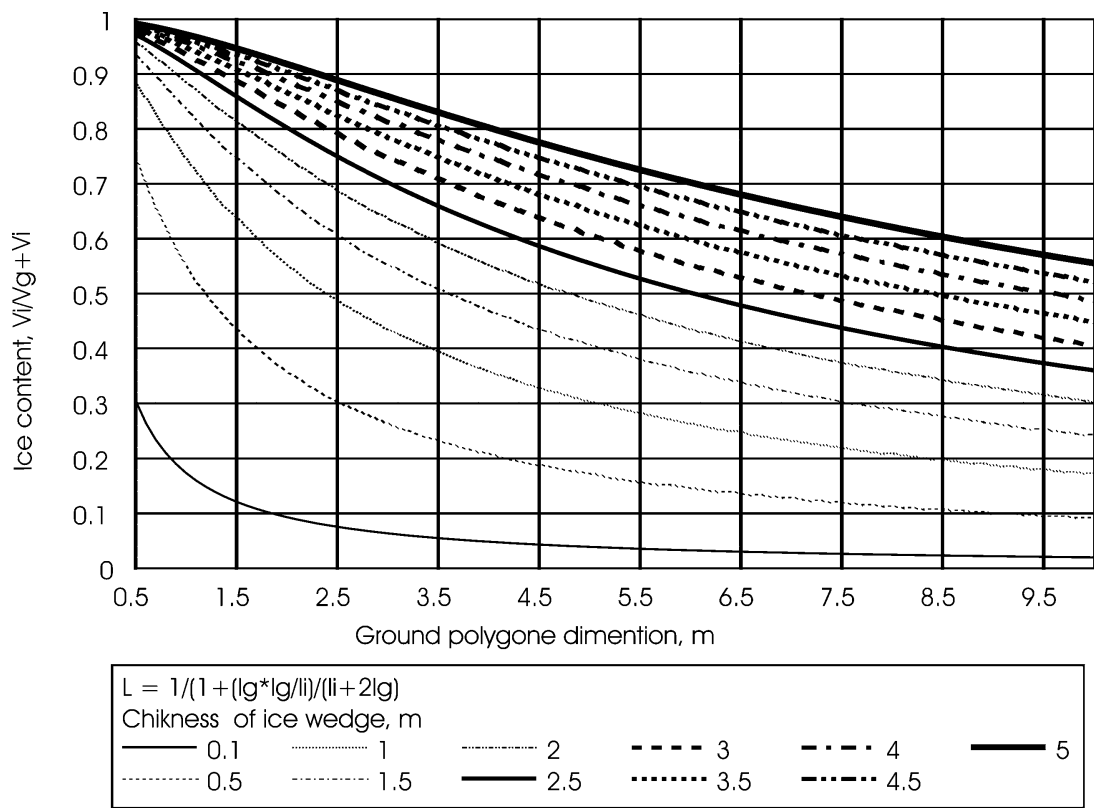

of unfrozen water was also taken into account using a technique found in Kudriavtsev et al.(1974). Integral values of ice content were determined using formulas recommended by the developers of the ACD project (Brown and Solomon 2000) for each coastal site (Table 2) to calculate the SFI.

\section{Coastline retreat rate}

In general, the coastal retreat rate is higher at the Malii Chukocii Cape site than at the Marre-Sale site. Also, the dynamics of permafrost erosion are characterized here by a wide scatter of erosion rate values (Fig. 1). The specific mechanisms of erosion determine the observable differences between the monitoring sites. Coastal erosion is close to the model with continuous erosion (Are 1985) at the Marre-Sale site. The main eroding agents at this site are thermal destruction and permanent wave effect. The monotonic changes of shore erosion are determined by the high contents of ice in permafrost, the rather low land surface level and the slope of the marine bottom (Fig. 1a). At the Malii Chukocii Cape site (Fig. 1b) the wave destruction of the high cliffs is mainly concentrated on incidental wind-induced storm surges under conditions of an extensive bank. Thus, the erosion rate has very high variability. Data on CLRR (e.g. Fig. 1) from the key site profiles were used to calculate SFI during the monitoring period. These data were used as input for the Markovchain based model to calculate simulated RRTS.

\section{Markov-chain based model of RRTS}

Design of the model and program algorithm

The Markov characteristic of the RRTS allows these sequences to be simulated using a stochastic approach.
The mathematical formalism for geological Markov models has been developed in detail, and has been used for geological studies by Vistelius (1967), Tsyganov (1968), Harbaugh and Bonham-Carter (1970), Elfeki and Dekking (2001), Ferrero and Gallagher (2002), and many other researchers. The particular algorithm used here is derived from Vistelius (1967) and Harbaugh and Bonham-Carter (1970) with the addition of units for the discrete transformation of a continuous time sequence. The postulate will be assumed hereinafter, that the matrices of transient probabilities correspond to the stationary random process. The matrix does not change depending on the length of the initial sequence in the case of a stationary random process (Polyak 1996). The algorithm consists of the following steps: (1) transformation of the observed RRTS into the discrete form of the retreat rate parameter; (2) testing of the discrete sequence for Markov characteristic; (3) calculations of matrices of transient probabilities in the natural and cumulative form; (4) calculation of a simulated discrete sequence using the transient probability matrices; (5) calculation of a simulated sequence of RRTS; and (6) verification and comparison of statistical parameters for the prototype (i.e. the measured series) and simulated ones.

Transformation of the RRTS into the discrete form

The measured values of CLRR in the sequence ( $\mathrm{m}$ per year) were transformed into the discontinuous series by division into equal parts (ranges of the retreat rate). Division of each sequence into $K$ equal ranges (Harbaugh and Bonham-Carter 1970): $K=3$ only were used in this work because the accessible time sequences were rather short (no more than 33 years), but enough to 
build a working model. The appropriate size of matrices was $3 \times 3$, and the number of degrees of freedoms $f=4$.

Testing of RRTS for Markov characteristic

The Markov process begins with a sequence of discrete conditions of a system, in which each subsequent condition does not depend on the previous condition. However, in a Markov process, each previous condition (or some previous conditions) determines the probability of transition to a certain consequent condition (Korn and Korn 1987). Thus, the Markov sequence has probabilistic memory (Harbaugh and Bonham-Carter 1970). The standard test was used to check the discrete sequences of CLRR for Markov characteristic. The test is based on checking the hypothesis that the events in the examined sequence are absolutely independent. In the sequence of independent events:

$\eta=2 \sum_{i, j}^{m} n_{i, j} \ln \left(\frac{p_{i, j}}{p_{j}}\right)$

where $p_{i j}=$ the probability corresponding to row $i$ and column $j$ of the matrix of transient probability; $p_{j}=$ $\sum_{i=1}^{m} n_{i j} / \sum_{i, j}^{m} n_{i, j}$ gives the absolute probability corresponding to column $j ; n_{i, j}=$ the transient frequency for row $i$ and column $j$; and $m=$ the total number of events in the sequence (Anderson and Goodman 1957). If $\eta>\chi^{2}$ for the significance level of $\chi^{2}$ under the appropriate number of degrees of freedom, $f=(m-1)^{2}$, then the hypothesis is not true, and the examined sequence may be a 1st order Markov chain (Harbaugh and Bonham-Carter 1970). We used the standard critical level of chi-square statistics on $\alpha=0.05$ and corresponding $\chi^{2}=9.49$.

The test procedure used is described in a paper by Anderson and Goodman (1957). It can be illustrated by the following example. The total amplitude is divided into 3 ranges in the observed sequence of RRTS at the Marre-Sale site: $0-1,1-2$, and $>2$ (Table 3). The

Table 3 The observed CLRR time sequence at profile \#36, MarreSale monitoring profile

\begin{tabular}{llllll}
\hline Year & $\begin{array}{l}\text { CLRR } \\
\text { (m/year) }\end{array}$ & $\begin{array}{l}\text { Range of the } \\
\text { CLRR }\end{array}$ & Year & $\begin{array}{l}\text { CLRR } \\
\text { (m/year) }\end{array}$ & $\begin{array}{l}\text { Range of the } \\
\text { CLRR }\end{array}$ \\
\hline 1979 & 2.6 & 3 & 1991 & 2.6 & 3 \\
1980 & 1.6 & 2 & 1992 & 1.6 & 2 \\
1981 & 1.8 & 2 & 1993 & 0.7 & 1 \\
1982 & 2.7 & 3 & 1994 & 2.5 & 3 \\
1983 & 1.7 & 2 & 1995 & 1.7 & 2 \\
1984 & 2.4 & 3 & 1996 & 0.8 & 1 \\
1985 & 2.5 & 3 & 1997 & 2.7 & 3 \\
1986 & 1.7 & 2 & 1998 & 1.6 & 2 \\
1987 & 0.7 & 1 & 1999 & 0.5 & 1 \\
1988 & 0.3 & 1 & 2000 & 2.5 & 3 \\
1989 & 1.6 & 2 & 2001 & 0.6 & 1 \\
1990 & 0.5 & 1 & & & \\
\hline
\end{tabular}

Table 4 Matrices of frequency and transient probability of observed RRTS at the Marre-Sale monitoring site

\begin{tabular}{llllll}
\hline \multicolumn{2}{c}{ Frequency matrix } & \multicolumn{3}{c}{ Matrix of transient probability } \\
\hline 1 & 1 & 4 & 0.142 & 0.142 & 0.571 \\
5 & 1 & 2 & 0.625 & 0.125 & 0.250 \\
1 & 6 & 1 & 0.142 & 0.857 & 0.142 \\
\hline
\end{tabular}

discrete sequence is a row of the ranges of CLRR. It is used to calculate both the frequency matrix and the transient probability matrix (Table 4).

The calculated value of $\eta=11.95$ is more that the critical level of $\chi^{2}=9.49$. The test thus shows that the examined sequences can be described as 1st order Markov-chains.

Calculations of matrices of transient probabilities in the natural and cumulative form

The calculation of the transient probability is based on the frequency distribution of the transition between the ranges of retreat rate in the time sequence. The transformation of the matrices into the cumulative form is an easy addition of the transient probabilities in the matrix rows until one in the last value (Harbaugh and BonhamCarter 1970).

\section{Calculation of a simulated sequence of RRTS}

The algorithm by Harbaugh and Bonham-Carter (1970) was used for calculation of the simulated RRTS in the discontinuous form on the basis of the matrices of transient probability. The procedure is based on the selection of random values according to the appropriate probability for each step of the simulated sequence. The calculated retreat rates (m per year) are random values within each range of the observed CLRR.

\section{Program realization}

The program itself is written in Visual Basic for Applications (VBA) and is available as an "add-on" module for the MS Excel environment. The freely distributed files are ready for operation, and contain all basic steps of the algorithm, an example of input data, and a short manual. They are available by e-mail query (v.ostroumov@rambler.ru).

Fig. 4 Simulated time series of coastline retreat rates at the key site Marre-Sale: a, b, c raw data; d, e, f same data after 21-point smoothing 
Table 5 Comparison of measured and simulated time series of the coastal retreat rates

\begin{tabular}{|c|c|c|c|c|}
\hline & \multicolumn{2}{|c|}{ Marre-Sale } & \multicolumn{2}{|c|}{ Malii Chukochii Cape } \\
\hline & Measured & Simulated & Measured & Simulated \\
\hline $\begin{array}{l}\text { Average retreat rate } \\
\text { of coast, } m \text { per year }\end{array}$ & 1.640 & 1.645 & 4.333 & 4.307 \\
\hline Standard deviation & 0.6271 & 0.6325 & 2.113 & 1.972 \\
\hline $\begin{array}{l}\text { Length of the } \\
\text { observed time } \\
\text { sequence, yrs }\end{array}$ & 23 & & 15 & \\
\hline$t$-test & 0.02450 & & 0.03340 & \\
\hline $\begin{array}{l}\text { Probability of the } \\
\text { certain difference }\end{array}$ & 0.9806 & & 0.9735 & \\
\hline
\end{tabular}

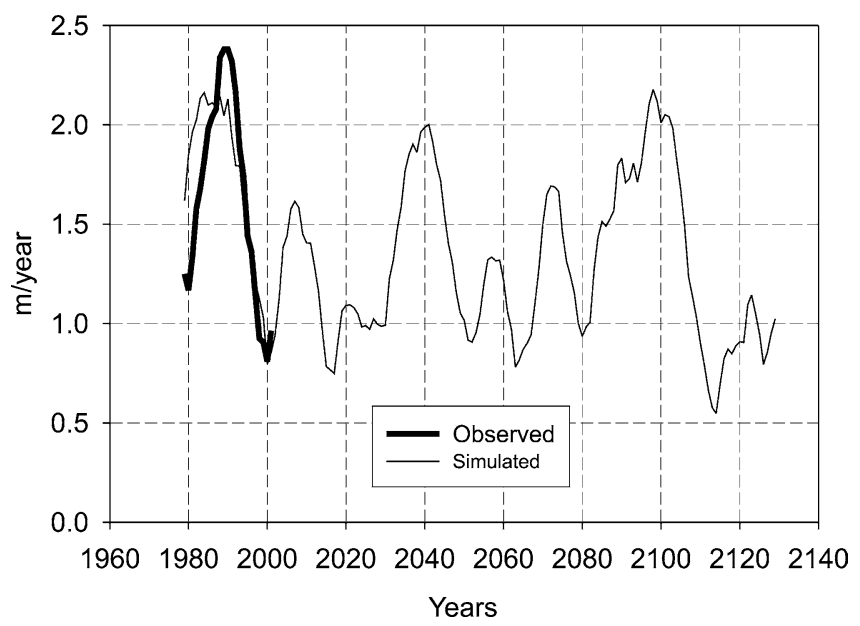

Fig. 3 Simulated and measured sequences of the coastline retreat rates, monitoring profile 1, key site Marre-Sale
Comparison of the simulated RRTS with the prototype

The simulated retreat rate series were compared with the initial sequences (monitoring data). Harbaugh and Bonham-Carter (1970) recommended the average values, standard deviations and $t$-test for such comparisons. Table 5 contains an example of the comparison between simulated and observed time series of the CLRR. No difference was found: the model reflects the dynamics of coastal line adequately.

\section{CLRR dynamics modeling results}

The Markov dynamic models reveal all sets of possible changes to a system that are determined by a matrix of transient probabilities. The increase of the length of a simulated series does not change the style of dynamics in the case of fixed random processes. Long simulated sequences can be used to reflect a greater number of possible transitions (Polyak 1996; Harbaugh and Bonham-Carter 1970). Dynamic curves were calculated for each coastal profile for a 150 -year period (Fig. 3). This length of simulated time series approximately corresponds to the order of characteristic time of shore erosion processes (Shur 1984).

A comparison of the calculated sequence with the monitoring data shows that the model is adequate within the length of the observed series (solid line, Fig. 3). Such comparisons show that both curves have a similar form and are characterized by close average values $(1.49 \mathrm{~m}$ per year and $1.62 \mathrm{~m}$ per year for observed and simulated sequence, respectively).

Examples of simulated curves of CLRR dynamics are presented in Figs. 4 and 5. The simulated series are used for the estimation of the intensity of sediment flux.
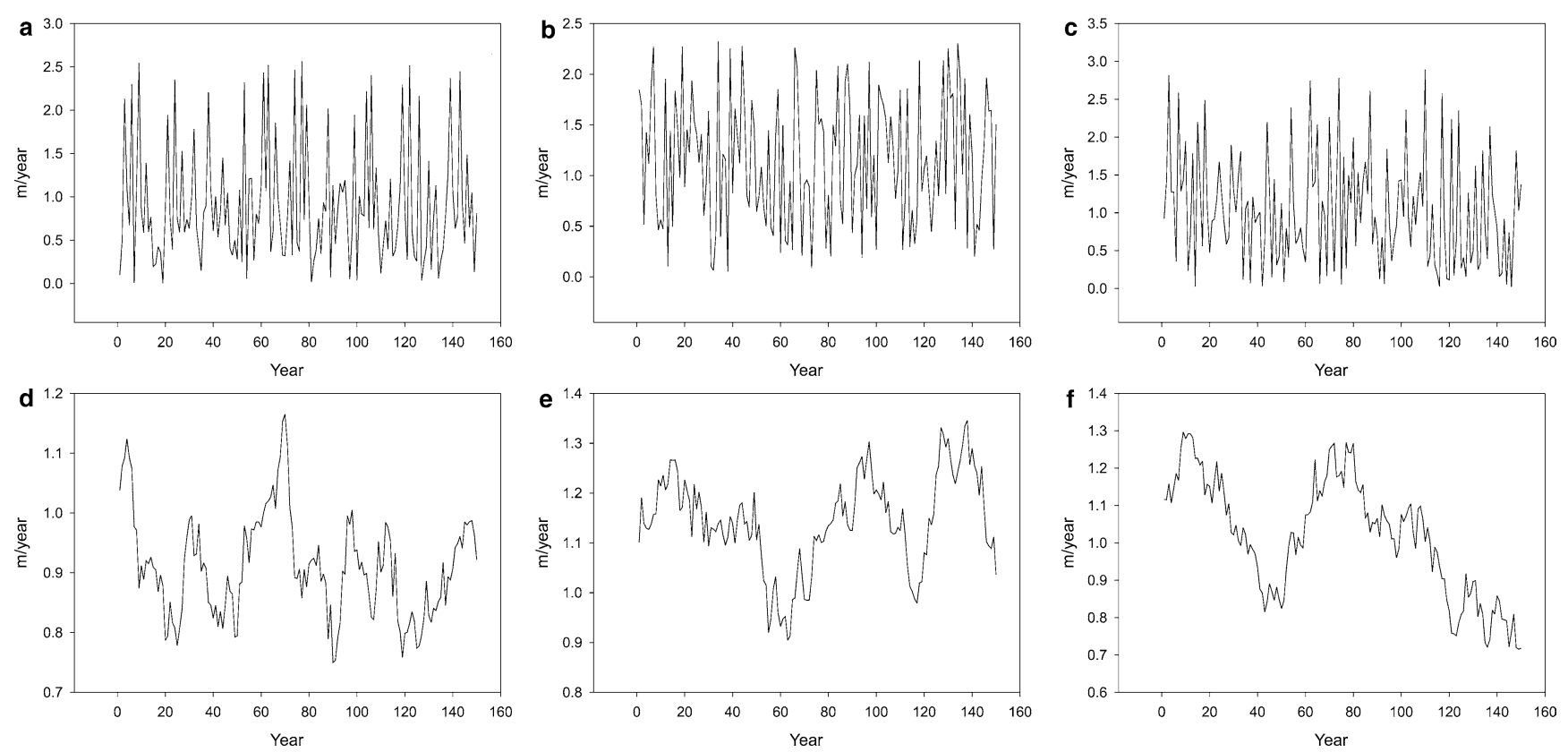

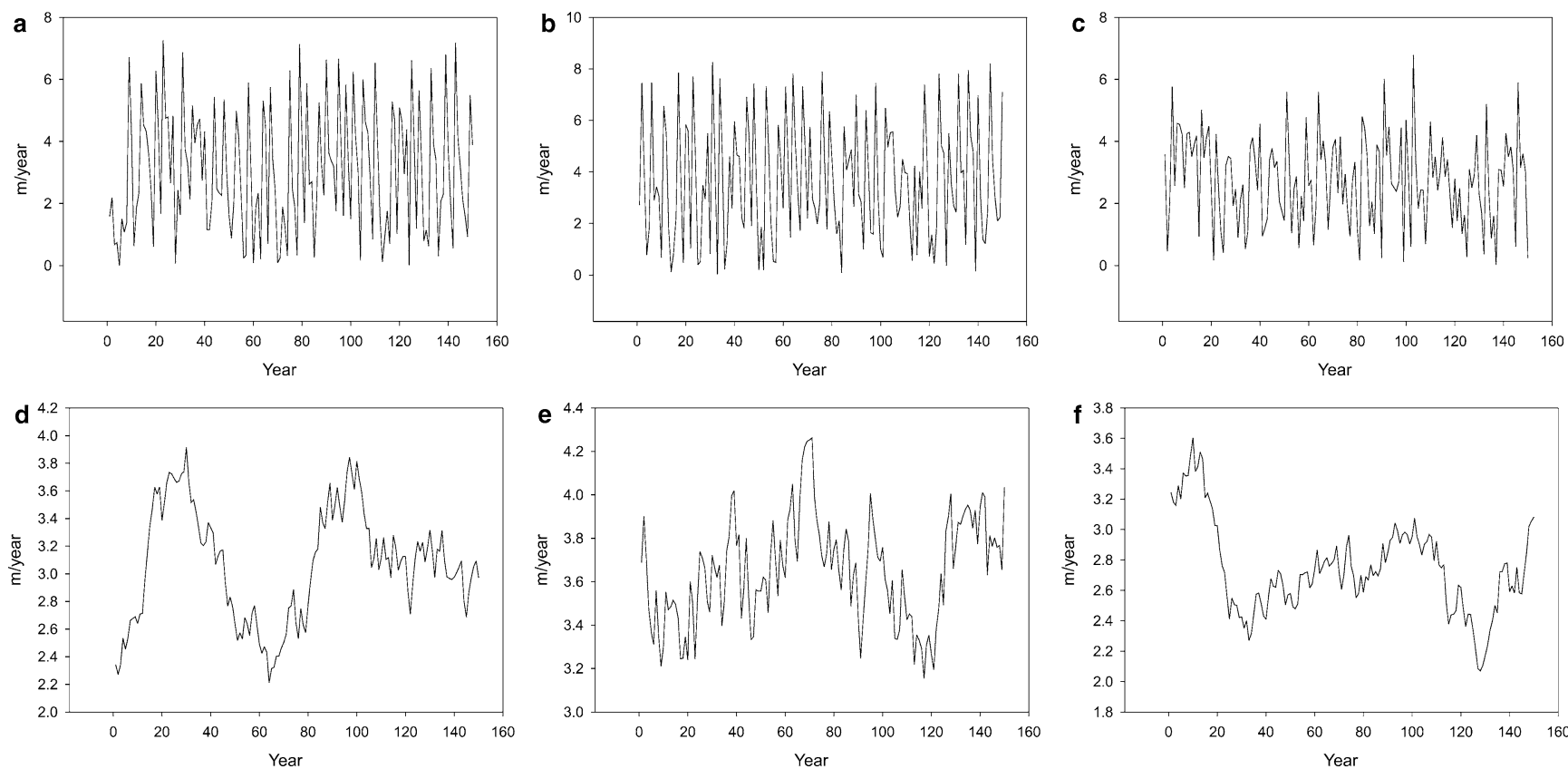

Fig. 5 Simulated time series of coastline retreat rates at the key site Malii Churochii Cape: a, b, c raw data; d, e, f same data after 21point smoothing

The abovementioned differences (see Coastline retreat rate) are illustrated in the comparison between the MarreSale and Malii Chukocii Cape sites in the average values of SFI and their deviations. Both average and deviation are higher at the Malii Chokocii Cape site (Fig. 6).

\section{Conclusions}

The intensity of sediment input is calculated using coastal monitoring data. It varies from $10-12$ to $23-$ $27 \mathrm{t} \mathrm{m}^{-1}$ per year at the Marre-Sale key site (Kara Sea) and from $35-42$ to $137-149 \mathrm{t} \mathrm{m}^{-1}$ per year at Malii Chukochii Cape key site (East Siberian Sea). These calculations underestimate the actual values because the manner in which input data were selected or estimated, in the case of missing data, was deliberately conservative. The observed time series of coastline retreat rate were found to possess Markov characteristic. This allows the use of Markov formalism for modeling the shore erosion process.

The Markov chain based model adequately describes the coastline dynamics. It was used to simulate sequences of coastal retreat rate of permafrost coasts and the resulting sediment input to the sea basin. The simulated time sequences of coastal retreat reflect features of the dynamics unique to each observing site. The application of this model should be considered for characterization of profiles and sites where shore dynamics are being measured.
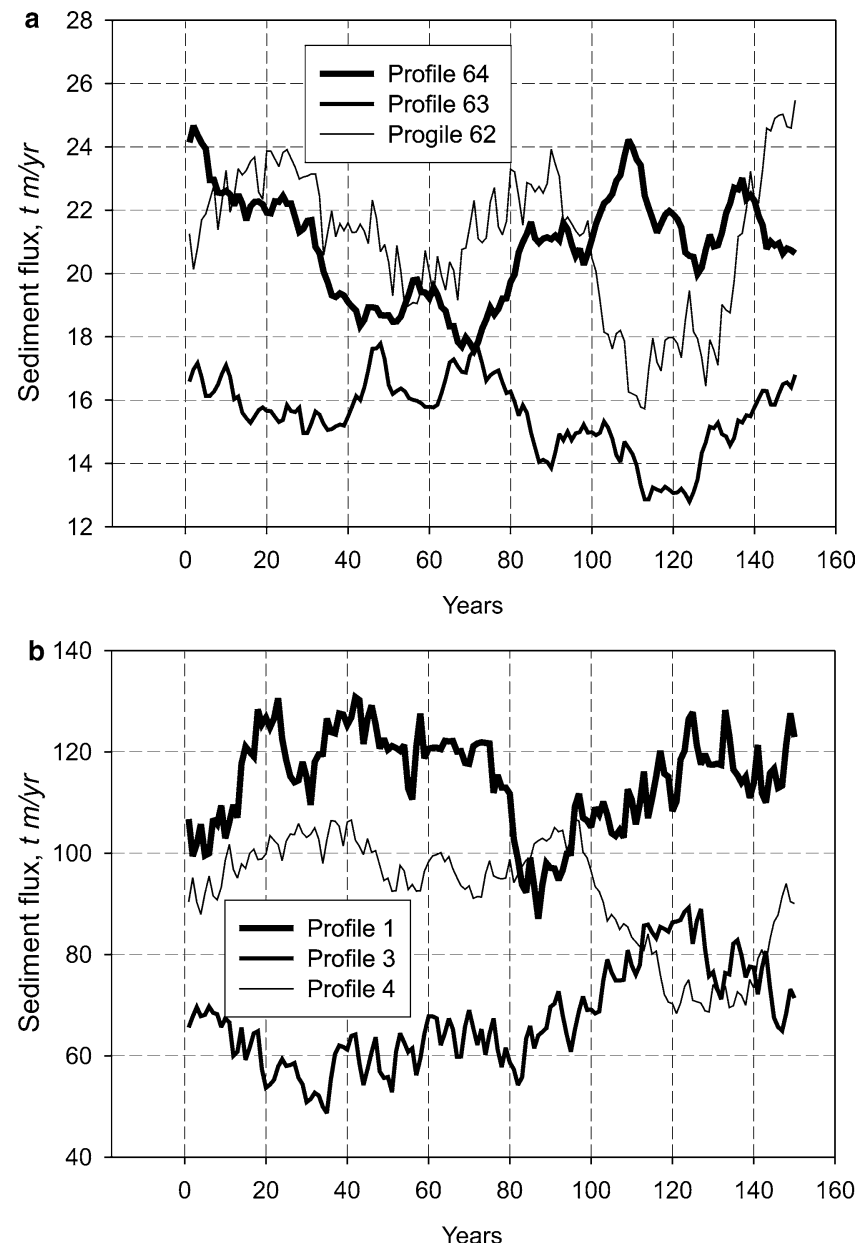

Fig. 6 Simulated sediment flux intensity at the key sites Marre-Sale a and Malii Chukochii Cape b 
Acknowledgements The authors would like to thank Dr. Stas Gubin, Dr. David Gilichinsky, Dr. Misha Grigoriev and Dr. Stanislav Ogorodov who kindly furnished the coastal monitoring data for testing of the model. Special thanks go to Dr. Pavel Grabarnik and Hugues Lantuit for helpful discussions on the Markov modeling technique and on the application of stochastic models for the processing of coastal monitoring data. This work has been supported by the International Association for the Promotion of Cooperation with Scientists from the New Independent States of the former Soviet Union, Grant INTAS 01-2329.

\section{References}

Anderson TW, Goodman LA (1957) Statistical inference about Markov chains. Ann Math Stat 28:89-110

Are FE (1979) Thermal abrasion of coasts. Dr. of Sci. (Geography) Thesis, Moscow University, p 37

Are FE (1985) Principles of shore thermoabrasion forecast. Novosibirsk Nauka Press, p172

Are FE (1988) Thermal abrasion of sea costs (part 1). Polar Geography Geol 12:1-86

Are FE (1998) The contributing of shore thermoabrasion to the Laptev Sea sediment balance. Permafrost. In: Proceedings of the 7th International Conference, Yellowknife, pp 25-30

Arkhangelov AA (1977) Underground glaciation of the Kolyma Lowland. Problems of the Cryolythology 4, Moscow University Press, pp 26-57

Balobaev VT (1984) Calculation of thawing of ice rich grounds under water pools with an allowance for thermal residues. In: Coastal processes in cryolythozone. Nauka Press, Nosibirsk, pp 93-100

Brown J, Solomon S (2000) Arctic Coastal Dynamics-Report of an International Workshop, Woods Hole, MA, 2-4 November 1999. Geol Surv Can Open File 3929

Danilov ID, Komarov IA, Vlasenko AY (1997) Dynamics of the cryolytosphere in the area of continent-shelf interaction during last 25000 years. Earth Cryosphere 1(3):3-8

Danilov ID, Komarov IA, Vlasenko AY (2000) The cryolythozone of the East Siberian shelf during last 80000 years. Earth Cryosphere 4(1):18-23

Elfeki AMM, Dekking FM (2001) A Markov chain model for subsurface characterization: theory and applications. Math Geol 33(5):569-589

Ferrero CD, Gallagher KL (2002) Stochastic thermal history modeling 1: constraining heat flow histories and their uncertainty. Mar Petrol Geol 19(6):633-648

Gilichinsky DA (2002) Late Pleistocene cryobiosphere: permafrost as a habitat of viable microorganisms preservation. DSc (Geology) Thesis, Tumen, p 59

Harbaugh JW, Bonham-Carter G (1970) Computer simulation in geology. Wiley Interscience, New York, p 327

Kholodov AL, Rivkina EM (2004) Estimation of organic matter input in sea basin at thermal abrasion of shores of Laptev and East Siberian Seas. Earth Cryosphere (in press)

Klimovich VI, Prokofiev VA (2002) Numerical investigation of marine construction using a solution of hydrodynamic task of open flux and sediment transport. Reports of the B.G.Vedeneev VNIIG 240:135-145

Korn JL, Korn SA (1987) Handbook in mathematics, p 2317

Kudryavtsev VA, Garagulia LS, Kondrat'eva KA, Melamed VG (1974) Fundamentals of geocryological forecasting for engineering and geological purposes. Moscow University Press, p 431

Malinovskii DV (1982) Mathematical Modeling of thermal erosion. In: Thermal erosion of grounds. Moscow University Press, pp 135-145

Pavlidis YA, Leont'ev IO (2002) Prognosis of East Siberian shore development on the increase of sea level and climatic change. Bull RFBR 4:53-57
Pavlov AV (1998) Active Layer Monitoring in Northern West Siberia. Permafrost. In: Proceedings of the 7th International Conference, Yellowknife, pp 875-891

Pavlov AV, Vasiliev AA, Shur YL (1995) Monitoring of permafrost conditions of the west part of the Yamal Peninsula. In: The 25th Arctic Workshop. Laval University, Quebec, pp 144 147

Pfeiffer EM, Janssen H (1994) Characterization of organic carbon using the $\delta^{13} \mathrm{C}$-value of a permafrost site in the Kolyma-Indigirka Lowland, Northeast Siberia. In: Kimble JM, Ahrens RJ (eds) Proceedings of the meeting on the classification, correlation, and management of permafrost-affected soils. USDA, pp 90-98

Polyak I (1996) Computational statistics in climatology. Oxford University Press, New York, p 358

Rachold V, Grigoriev MN, Hubberten HW, Schirrmeister L (2003) Modern coastal organic carbon input to the Arctic Ocean. Rep Polar Mar Res 443:97

Razumov RO (1996) Dynamics of thermal abrasion sea coasts in a connection to features of geocryological and climatic conditions (on an example of Kolyma Bay, East Siberian Sea). PhD Thesis, Yakutsk, p 24

Razumov RO (2001) Model of dynamics of ice rich shores of Arctic Sea at the stationary climatic conditions. In: Proceedings of 2nd conference of Russian geocryologists, vol 2, pp 262-269

Sher AV(1997) Environmental restructuring at the Pleistocene/ Holocene boundary in the East-Siberian Arctic and its role in mammalian extinction. Communication 1. Earth Cryosphere 1(1):21-29

Shur YL (1984) Methods of study of the rate of coastal thermoerosion. Coastal processes in cryolythozone. Novosibirsk, Nauka, pp 5-12

Shur YL, Vasiliev AA (1984) New results of coastal destruction monitoring in cryolythozone. Coastal processes in cryolythozone. Novosibirsk, Nauka, pp 12-19

Solomon S (2003) A new shoreline change database for the Mackenzie-Beaufort Region, NWT, Canada. Rep Polar Mar Res 443:108-109

Sovershaev VA (1997) Western coast of the Yamal Peninsula. Evolution of sea coasts in Russia and their changes under possible global sea-level rise. Moscow, MSU, pp 202-220

Trofomov VT (ed) (1975) Yamal Peninsula. Engineering-geological review. Moscow, MSU, pp 276

Tsyganov RI (1968) Using Markov chain in describing slope processes. Izvestiia vysshikh uchebnykh zavedenii. Geologiia i razvedka 11(10):104-105

Vasiliev AA, Sautkin EV (1992) Thermoerosion of sea coasts at western Yamal. Methods of study of the cryogenic processes. VSEGINGEO, Moscow, pp 71-77

Vasiliev AA, Pokrovsky SI, and Shur YL (2001) Dynamics of thermoerosional coasts of Western Yamal. Earth Cryosphere $5(1): 44-52$

Vasiliev AA, Cherkashov GA, Vanshtein BG, Firsov YG, Ivanov MV (2002) Coastal dynamics in Marre-Sale, Kara Sea: a new observation program. Rep Polar Mar Res 413:78-79

Vasiliev A, Kanevskiy M, Firsov Y (2003) The mechanism of the sea coast destruction in Marre-Sale, Western Yamal. Rep Polar Mar Res 443:110-113

Vasiliev A, Kanevskiy M, Cherkashov G, Vanshtein B (2004) Coastal dynamics at the Barents and Kara Sea key sites (this volume)

Vistelius AB (1967) Studies in mathematical geology. Consultants Bureau, NY, p 294

Zenkovich VP (1946) Dynamics and morphology of sea coasts. V.1, Wave processes, p 271

Zigarev LA, Sovershaev VA (1984) Thermal abrasion destruction of the Arctic islands. In: Coastal processes in cryolythozone. Novosibirsk, Nauka, pp 31-38 